Article

\title{
Design, Preparation, and Evaluation of a Novel Elastomer with Bio-Based Diethyl Itaconate Aiming at High-Temperature Oil Resistance
}

\author{
Hui Yang ${ }^{1}$, Haijun Ji ${ }^{1}$, Xinxin Zhou ${ }^{1, *(\mathbb{D})}$, Weiwei Lei ${ }^{2, *}$, Liqun Zhang ${ }^{1}$ and Runguo Wang ${ }^{1, *}$ \\ 1 Beijing Advanced Innovation Center for Soft Matter Science and Engineering, State Key Laboratory of \\ Organic-Inorganic Composites, Beijing Laboratory of Biomedical Materials, Beijing University of Chemical \\ Technology, Beijing 100029, China; 2017310124@mail.buct.edu.cn (H.Y.); 2017210203@mail.buct.edu.cn (H.J.); \\ zhanglq@mail.buct.edu.cn (L.Z.) \\ 2 Hubei Key Laboratory of Polymer Materials, School of Materials Science \& Engineering, Hubei University, \\ Wuhan 430062, China \\ * Correspondence: wangrg@mail.buct.edu.cn (R.W.); zhouxinxin2011@126.com (X.Z.); \\ leiwwcaem@126.com (W.L.); Tel.: +86-10-6445-5618 (R.W.); 0086-15901273417 (X.Z.); 0086-13466558438 (W.L.)
}

Received: 15 October 2019; Accepted: 15 November 2019; Published: 17 November 2019

\begin{abstract}
A novel elastomer poly(diethyl itaconate-co-butyl acrylate-co-ethyl acrylate-co-glycidyl methacrylate) (PDEBEG) was designed and synthesized by redox emulsion polymerization based on bio-based diethyl itaconate, butyl acrylate, ethyl acrylate, and glycidyl methacrylate. The PDEBEG has a number average molecular weight of more than 200,000 and the yield is up to $96 \%$. It is easy to control the glass transition temperature of the PDEBEG, which is ranged from -25.2 to $-0.8^{\circ} \mathrm{C}$, by adjusting the monomer ratio. We prepared PDEBEG/CB composites by mixing PDEBEG with carbon black N330 and studied the oil resistance of the composites. The results show that the tensile strength and the elongation at break of the composites with $10 \mathrm{wt} \%$ diethyl itaconate can reach up to 14.5 MPa and 305\%, respectively. The mechanical properties and high-temperature oil resistance of the composites are superior to that of the commercially available acrylate rubber AR72LS.
\end{abstract}

Keywords: bio-based diethyl itaconate; redox emulsion polymerization; composite; mechanical properties; high-temperature oil-resistant

\section{Introduction}

Rubber material is an important strategic material for the national economy and the national defense industry, among which oil-resistant rubber takes a vital role. It is widely used to manufacture oil-resistant products in the automobile manufacturing, aerospace, and machinery industries, such as oil pipes, drums, and gaskets [1]. At present, the most commonly used rubber in oil seal materials is nitrile-butadiene rubber (NBR) [2], which has a good oil resistance, wear resistance, and weather resistance [3,4]. With the development of industrialization, especially in the automotive industry, the requirements for rubber oil resistance and heat resistance are getting more and more strict. In order to meet these requirements, rubber material has also undergone a great change from NBR to acrylate rubber (ACM) [5], methyl vinyl silicone rubber (MVQ) [6], fluororubber (FKM) [7], hydrogenated nitrile-butadiene rubber (HNBR) [8,9], and so on.

$\mathrm{ACM}$ is an elastomer obtained by copolymerization of acrylate monomers. It has excellent heat resistance, aging resistance, weather resistance, and UV resistance due to a saturated main chain structure [10]. Polar ester groups of side chains make ACM rubber oil-resistant. ACM is superior to NBR in heat resistance and aging resistance [11-13]. Compared with MVQ and FKM, ACM has better processing and mechanical properties. Furthermore, ACM has a relative low price, which is only $1 / 5$, 
$1 / 3$, and $1 / 12$ of the price of HNBR, MVQ, and FKM, respectively. Therefore, in recent years, ACM has been widely used and developed as an oil seal rubber [14].

The monomers used to synthesize oil-resistant rubbers are mainly derived from fossil resources. In order to reduce the dependence on petrochemical resources and maintain sustainable development in the rubber industry $[15,16]$, we urgently need to develop elastomers with bio-based content and engineering application potential to replace full petroleum-based elastomers [17-21]. At present, biochemicals capable of mass production mainly include: 1,3-propanediol, 1,4-butanediol [22,23], itaconic acid [24,25], sebacic acid [26], etc. Itaconic acid is a mass-product by fermentation from carbohydrates using Aspergillus terreus $[27,28]$. It has two carboxyl groups and one double bond in one molecule. As an unsaturated dicarboxylic organic acid, itaconic acid is capable of transforming into various derivatives. Itaconic acid and its derivatives, such as dialkyl itaconate, are expected to replace acrylic or methacrylic monomer to synthesize polymers. The functional carboxylic groups allow itaconic acid to undergo polycondensation with diols and diamines to prepare polyesters [29-33] and polyamides [34,35], respectively. By using the double bonds, itaconic acid can undergo free radical polymerization to prepare poly(itaconic acid). More commonly, dialkyl itaconate is used as a substitute for itaconic acid to homopolymerize or copolymerize with other unsaturated monomers by emulsion polymerization [24,36-38]. This emulsion polymerization, in which an isolated latex particle is formed by a micelle mechanism in an aqueous medium-based emulsion and a free polymerization reaction is carried out therein to produce a high polymer, is a green polymerization method. Nowadays, it includes surface-functionalized latexes [39], using a surfactant and organic solvent-free emulsion system [40], using lignin-based polymeric surfactants [41] and Disponil AFX non-ionic surfactants [42], which has been used widely by green emulsion polymerization. Lei et al. [43] synthesized bio-based elastomer PDEII with diethyl itaconate and isoprene and studied the oil resistance of the elastomer with various monomer ratios at different temperatures. The results showed that the high-temperature oil resistance and the thermal-oxidative aging performances of the elastomer deteriorated with the increase of the isoprene content, while the mechanical strength of the elastomer decreased with the decrease of the isoprene content. In addition, the introduction of isoprene provides the crosslink points and softens the macromolecule chains. In order to balance the high-temperature oil resistance, thermal-oxidative aging, and good elasticity of the elastomer with the crosslink points, the monomer isoprene should be replaced by other chemicals. In previous studies, the homopolymer of ethyl acrylate exhibited an excellent high-temperature oil resistance, while the homopolymer of butyl acrylate exhibited a good elasticity [1]. Furthermore, the monomers containing epoxy or active chlorine groups such as glycidyl methacrylate can be used to provide cross-linking points. Thus, a mixture of the ethyl acrylate, butyl acrylate, and glycidyl methacrylate is expected to replace the isoprene to copolymerize with diethyl itaconate, resulting in a novel elastomer with balanced overall properties.

In this work, a novel elastomer poly (diethyl itaconate-co-butyl acrylate-co-ethyl acrylate-co-glycidyl methacrylate) (PDEBEG) with bio-based content was synthesized by a redox emulsion polymerization. The butyl acrylate endows the PDEBEG with a low-temperature resistance. The mass ratio of diethyl itaconate to ethyl acrylate can adjust the mechanical properties and oil resistance performance of the PDEBEG. The oil resistance of the PDEBEG with various monomer ratios was investigated. In addition, a commercially available acrylate rubber AR72LS was used as a reference to evaluate the mechanical properties and oil resistance of the PDEBEG. The PDEBEG elastomer is expected to be used for seals, radiators, and hoses. The design and preparation route of the novel oil-resistant elastomer is shown in Figure 1. 


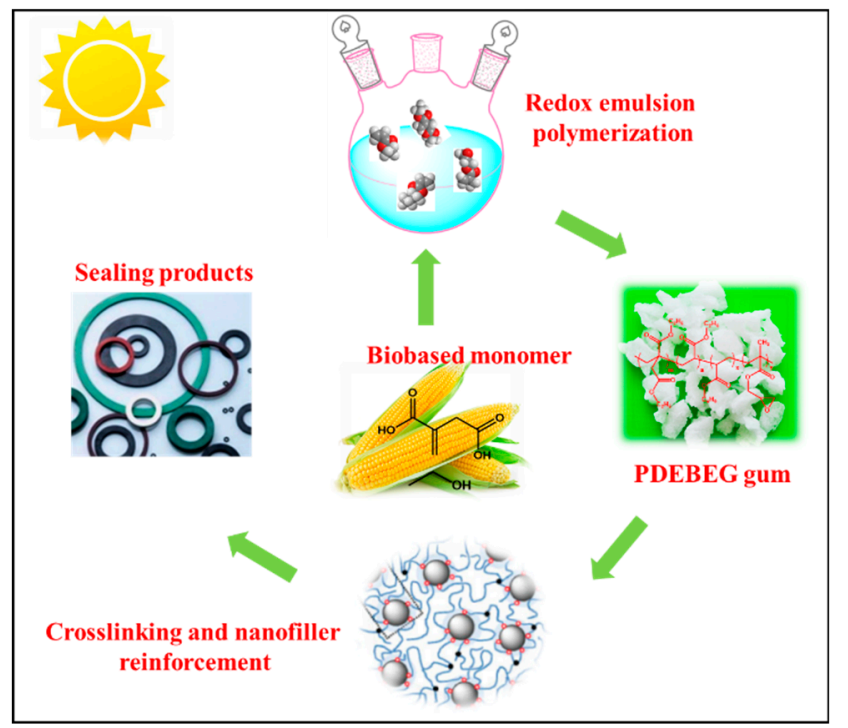

Figure 1. Design and preparation route of the novel elastomer with bio-based diethyl itaconate.

\section{Materials and Methods}

\subsection{Materials}

Diethyl itaconate (DEI, purity of 98\%) was purchased from Sigma-Aldrich Co. (Darmstadt, Germany). Ethyl acrylate (EA, purity of 99\%) was purchased from Aladdin Industrial Co. (Shanghai, China). Glycidyl methacrylate (GMA, purity of 97\%) was purchased from Aladdin Industrial Co. (Shanghai, China) and passed through a neutral alumina column before use. Butyl acrylate (BA, purity of 99\%) was purchased from Aladdin Industrial Co. (Shanghai, China) and purified by distillation under reduced pressure. Sodium dodecyl benzenesulfonate (SDBS, purity of 95\%) was purchased from Aladdin Industrial Co. (Shanghai, China) Ferric ethylene diamine tetraacetic acid salt (Fe-EDTA), sodium hydroxymethanesulfinate (SHS), tert-butyl hydroperoxide (TBH), and hydroxylamine (HA) were bought from Sigma-Aldrich Co. (Darmstadt, Germany) and used as received. Acrylate rubber AR72LS was purchased from ZEON Co. (Tokyo, Japan). Standard Oil 3\# for ASTM oil resistance performance test of elastomer was supplied by Japan Sun Oil (Tokyo, Japan).

\subsection{Synthesis of Poly(diethyl itaconate/butyl acrylate/ethyl acrylate/glycidyl methacrylate) (PDEBEG)}

The synthesis of the PDEBEG was carried out using the mass ratios of DEI/EA/BA/GMA shown in Table 1. The polymerization reaction is shown in Figure 2. Deionized water $(250.0$ g, provided by Beijing University of Chemical Technology, Beijing, China), SDBS (3.2 g), Fe-EDTA solution (8.0 g, concentration of aqueous solution was $1.0 \mathrm{wt} \%)$, SHS solution ( $4.0 \mathrm{~g}$, concentration of aqueous solution was $10.0 \mathrm{wt} \%$ ), and a mixture of the comonomers (DEI, EA, BA, and GMA) were added into a three-neck glass flask under nitrogen atmosphere, and then the emulsion system was stirred at $400 \mathrm{rpm}$ for $1 \mathrm{~h}$. Once the initiator TBH was injected into the flask, the stirring rate was reduced to $210 \mathrm{rpm}$. After $8 \mathrm{~h}$, the polymerization reaction was terminated by HA $(0.4 \mathrm{~g})$, and the PDEBEG latex was obtained. The PDEBEG latex was then coagulated by ethanol to obtain the wet PDEBEG elastomer. It was washed by ethanol to remove impurities and then dried in a vacuum oven at $60^{\circ} \mathrm{C}$ for $24 \mathrm{~h}$ to obtain the PDEBEG. 
Table 1. Mass ratio of monomers for redox-initiated emulsion polymerization of PDEBEG.

\begin{tabular}{ccccc}
\hline Ingredients & $\begin{array}{c}\text { Diethyl Itaconate } \\
(\mathbf{w t} \%)\end{array}$ & $\begin{array}{c}\text { Ethyl Acrylate } \\
(\mathbf{w t} \%)\end{array}$ & $\begin{array}{c}\text { Butyl Acrylate } \\
\mathbf{( w t} \%)\end{array}$ & $\begin{array}{c}\text { Glycidyl Methacrylate } \\
(\mathbf{w t} \% \mathbf{)}\end{array}$ \\
\hline PDEBEG-50 $^{\text {a }}$ & 50 & 10 & 40 & 2 \\
PDEBEG-40 & 40 & 20 & 40 & 2 \\
PDEBEG-30 & 30 & 30 & 40 & 2 \\
PDEBEG-20 & 20 & 40 & 40 & 2 \\
PDEBEG-10 & 10 & 50 & 40 & 2 \\
PDEBEG-0 & 0 & 60 & 40 & 2 \\
\hline
\end{tabular}

a The feed fraction of the diethyl itaconate, ethyl acrylate, and butyl acrylate for the PDEBEG was $50 \mathrm{wt} \%, 10 \mathrm{wt} \%$, and $40 \mathrm{wt} \%$, respectively, while $2 \mathrm{wt} \%$ of glycidyl methacrylate was introduced. The number (50) in the PDEBEG-50 indicates the proportion of diethyl itaconate (bio-based content) in the feeding process. The rest is the same as above.

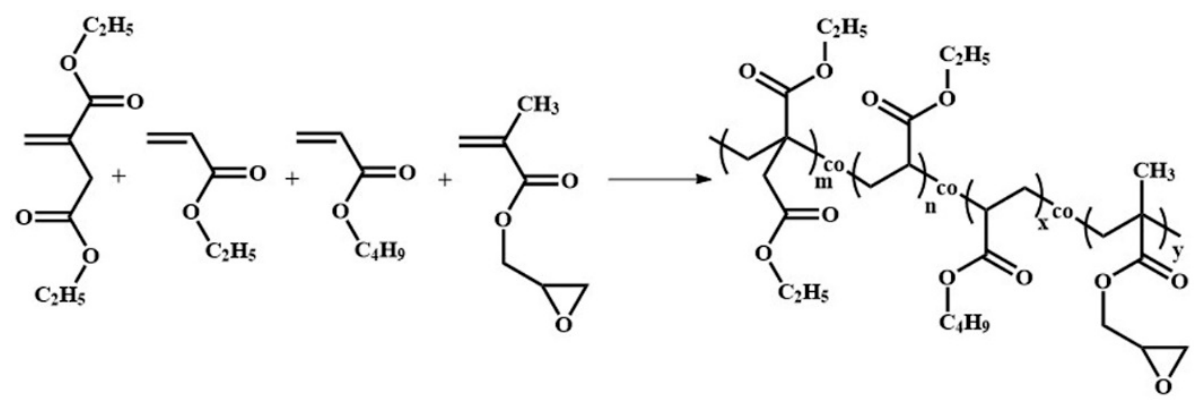

Figure 2. Reaction formula of PDEBEG by redox-initiated emulsion polymerization.

\subsection{Preparation of the PDEBEG/CB Composites}

The compounding formula of the PDEBEG/CB composites is shown in Table 2. First, carbon black (CB) was kneaded with the PDEBEG in a Haake internal mixer for 8 min to obtain a mixture. Second, the other additives were kneaded with the mixture to obtain PDEBEG/CB compound. Finally, the PDEBEG/CB compound was cured under $15 \mathrm{MPa}$ at $180^{\circ} \mathrm{C}$ to prepare PDEBEG/CB composite. The cure time is determined by a rotor-less vulcanizer.

Table 2. Recipe of the PDEBEG/CB composites.

\begin{tabular}{cc}
\hline Ingredients & Loading (phr) ${ }^{\text {a }}$ \\
\hline PDEBEG & 100.0 \\
N330 & 60.0 \\
stearic acid & 1.0 \\
antioxidant 445 & 1.0 \\
zinc dibutyl dithiocaarbamate & 2.5 \\
Sulfur & 1.0 \\
\hline${ }^{a}$ phr is the part per hundred of rubber.
\end{tabular}

\subsection{Measurements and Characterization}

\subsubsection{Gel Permeation Chromatography (GPC)}

The molecular weights of PDEBEG were determined by GPC measurements on a Waters Breeze instrument equipped with three water columns (Styragel HT3_HT5_HT6E) using tetrahydrofuran (THF) as the eluent $(1.0 \mathrm{~mL} / \mathrm{min}$ ) and a Waters 2410 refractive index detector (Water, Milford, MA, USA). A polystyrene standard was used for calibration. 


\subsubsection{Fourier Transform Infrared Spectroscopy (FT-IR)}

Fourier transform infrared spectroscopy (FT-IR) analysis was performed on an FT-IT spectrometer (Tensor 27, Bruker, Rheinstetten, Germany). The scan range was $4000-600 \mathrm{~cm}^{-1}$ with resolution of $4 \mathrm{~cm}^{-1}$.

2.4.3. Proton Nuclear Magnetic Resonance $\left({ }^{1} \mathrm{H}\right.$ NMR) Spectra

Proton nuclear magnetic resonance $\left({ }^{1} \mathrm{H}\right.$ NMR) spectra of PDEBEG with deuterated chloroform $\left(\mathrm{CDCl}_{3}\right)$ as the solvent were recorded on a Bruker AV400 (Rheinstetten, Germany) spectrometer at room temperature.

\subsubsection{Thermal Performance}

Different scanning calorimetry (DSC) measurements were performed with a Mettler Toledo (Greifensee, Switzerland) DSC instrument under a nitrogen atmosphere at a heating rate of $10^{\circ} \mathrm{C} / \mathrm{min}$ from -80 to $150{ }^{\circ} \mathrm{C}$. Thermal stability was evaluated by thermogravimetric analysis (TGA, Mettler Toledo International Inc., Greifensee, Switzerland). Samples of $10 \mathrm{mg}$ were heated from 30 to $600{ }^{\circ} \mathrm{C}$ at a heating rate of $10^{\circ} \mathrm{C} / \mathrm{min}$ under nitrogen atmosphere.

\subsubsection{Curing Characteristics}

The curing characteristics of the PDEBEG/CB compounds were measured at $180^{\circ} \mathrm{C}$ using a P3555B2 disc vulkameter (Beijing Huanfeng Chemical Machinery Trial Plant, Beijing, China).

\subsubsection{Mechanical Properties}

The tensile mechanical properties of the PDEBEG/CB compounds were investigated on the dumbbell specimens (ca. $25 \times 6 \times 2 \mathrm{~mm}$ ) with a SANS CMT 4104 electrical tensile instrument at room temperature and a tensile rate of $500 \mathrm{~mm} / \mathrm{min}$ according to ISO/DIS 37-1990. Hardness characterization was made by Rockwell hardness tester (Bareiss Prufgeratebau GmbH, Oberdischingen, Germany) using a $6 \mathrm{~mm}$ plate-shaped material in height gauge. In the measurement of permanent set, the fractured sample was placed for $3 \mathrm{~min}$, the two parts of the fracture were fitted together, and the length between two parallel lines after the anastomosis was measured with a measuring instrument, which was calculated by the Equation:

$$
E_{b}=\frac{100\left(L_{b}-L_{0}\right)}{L_{0}}
$$

where $E_{b}$ stands for the elongation at break, $L_{b}$ stands for the gauge length at the time of sample fracture, and $L_{0}$ stands for the initial gauge length of the sample.

\subsubsection{Rubber Process Analyzer (RPA)}

Strain sweep experiments (storage modulus $\left(G^{\prime}\right)$ as a function of scanning strain) were performed on vulcanizates by an RPA2000 rubber process analyzer (Alpha Technologies Corporation, Akron, OH, USA) at $60^{\circ} \mathrm{C}$.

\subsubsection{Scanning Electron Microscopy (SEM)}

The morphology of the blends was determined by scanning electron microscopy (SEM, S4800 Hitachi Co., Tokyo, Japan) at $10 \mathrm{kV}$. After immersing in liquid nitrogen for $5 \mathrm{~min}$, notched samples were fractured by vice and then sprayed with a thin gold layer.

\subsubsection{Oil Resistance Test}

Oil resistance of vulcanizates was carried out according to GB/T 1690-2010. Tensile test pieces of the blends were immersed in ASTM oil 3\# at $150^{\circ} \mathrm{C}$ for $72 \mathrm{~h}$. After completion of the aging, the test 
specimen was cooled to room temperature and blotted with filter paper. The mechanical properties and hardness of the aged samples were measured at $25^{\circ} \mathrm{C}$, as described above.

\section{Results and Discussion}

\subsection{Synthesis and Characterization of the PDEBEG}

Redox-initiated emulsion polymerization was carried out at $30{ }^{\circ} \mathrm{C}$ to synthesize the PDEBEG elastomer. We used $40 \mathrm{wt} \%$ butyl acrylate to ensure the low-temperature resistance and certain elasticity of the elastomer, and adjusted the ratio of diethyl itaconate to ethyl acrylate to optimize the mechanical properties and oil resistance of the elastomer.

As shown in Table 3, the number average molecular weight of the PDEBEG is more than 200,000, the yield is up to $96 \%$, and the molecular polydispersity index $(\nexists)$ is between 2.5 and 4.0. The more the amount of DEI introduced, the lower gel content of PDEBEG. The introduction of DEI is beneficial to reduce the gel content of the elastomer. It can be explained by the increase of the $T g$ and the decrease of the molecular weight with the increase of DEI content, which decreased the possibility of macromolecular entanglements.

Table 3. Molecular weight, yield, and composition of redox-initiated PDEBEG.

\begin{tabular}{ccccc}
\hline Sample & $\boldsymbol{M}_{\mathbf{n}} \mathbf{1 0}^{\mathbf{4}}$ & $\boldsymbol{\Xi}^{\mathbf{a}}$ & Yield/\% & Gel Content/\% \\
\hline PDEBEG-50 & 23.7 & 3.86 & 96.1 & 7 \\
PDEBEG-40 & 30.6 & 3.54 & 97.5 & 12 \\
PDEBEG-30 & 31.9 & 3.41 & 98.2 & 14 \\
PDEBEG-20 & 51.7 & 3.03 & 97.8 & 23 \\
PDEBEG-10 & 49.7 & 3.61 & 97.6 & 38 \\
PDEBEG-0 & 70.2 & 2.84 & 98.2 & 46 \\
\hline \multicolumn{4}{c}{${ }^{a} \emptyset$ stands for polydispersity index (Mw/Mn). }
\end{tabular}

The FT-IR spectra of the PDEBEG are displayed in Figure 3. The absorption peaks at 2951, 2924, and $2863 \mathrm{~cm}^{-1}$ are attributed to the stretching vibrations of $-\mathrm{CH}_{3},-\mathrm{CH}_{2}$, and $-\mathrm{CH}$ of the PDEBEG, respectively. Characteristic peaks are found at $1734 \mathrm{~cm}^{-1}(\mathrm{C}=\mathrm{O}$ ester), while peaks at 1029 and 1168 $\mathrm{cm}^{-1}$ are attributed to the $\mathrm{C}-\mathrm{O}-\mathrm{C}$ symmetrical and antisymmetric stretching vibration of PDEBEG, respectively. The small peak at $911 \mathrm{~cm}^{-1}$ corresponds to the ring vibration of the epoxy group. The results indicate that GMA has been successfully introduced into the polymer chains.

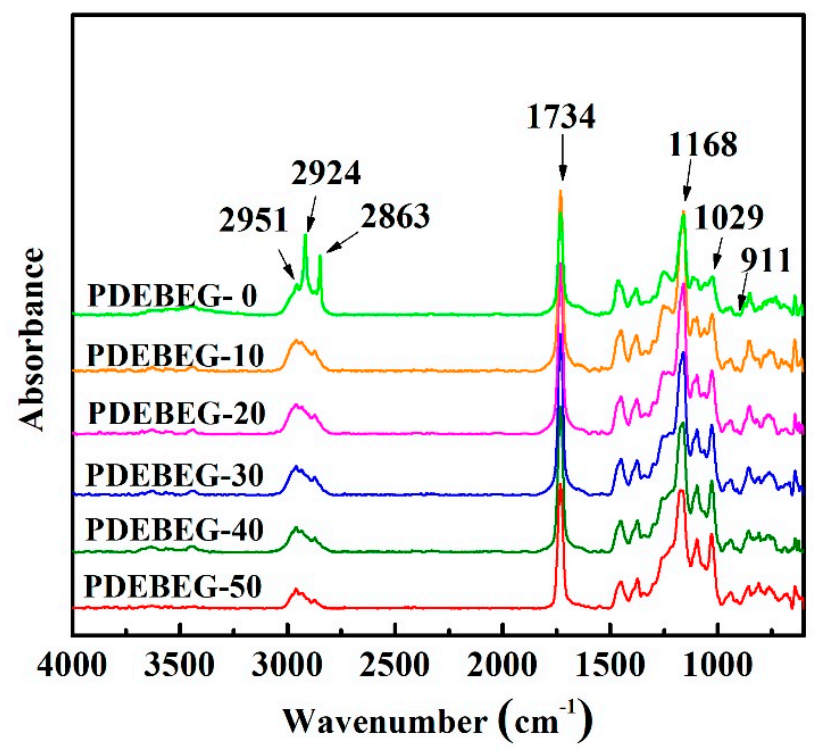

Figure 3. FT-IR spectra of PDEBEG. 
The chemical structures and compositions of the PDEBEG were further determined by using ${ }^{1} \mathrm{H}$ NMR spectroscopy. Figure 4 shows the ${ }^{1} \mathrm{H}$ NMR spectrum of PDEBEG-30. The signals at 3.68, 4.08, and $1.20 \mathrm{ppm}$ correspond to the protons of the methylene and methyl groups in diethyl itaconate. Those at 3.97, 1.47, 1.19, and $0.90 \mathrm{ppm}$ are assigned to the protons of the methylene and methyl groups in butyl acrylate of the PDEBEG chains. Those of the protons of the methylene and methyl groups in ethyl acrylate appear at 4.06 and $1.21 \mathrm{ppm}$, respectively. The small peaks at $3.82 \mathrm{ppm}$ originate from the protons of an epoxy group's adjacent methylene, indicating that GMA has been successfully introduced into the polymer chains.

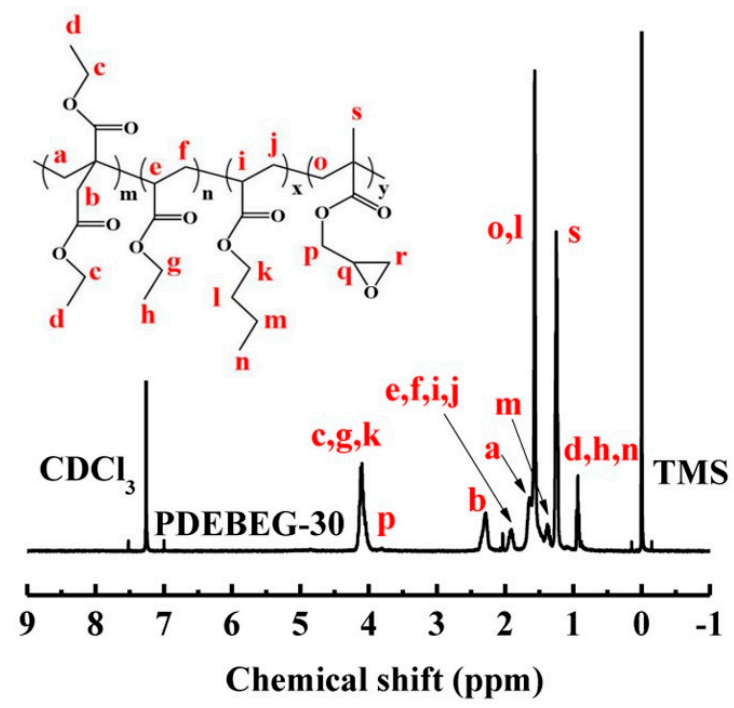

Figure 4. ${ }^{1} \mathrm{H}$ NMR spectra of PDEBEG-30.

\subsection{Thermal Performance of the PDEBEG}

The glass transition temperature $(T g)$ determines whether a material is an elastomer at the end-use temperature. In Figure 5, nonisothermal DSC results from -40 to $40{ }^{\circ} \mathrm{C}$ for PDEBEG samples exhibited a completely amorphous structure. $T g$ increases with the increase of the DEI content from -25.2 to $-0.8^{\circ} \mathrm{C}$. The introduction of the ester groups is responsible for the increase of $T g$ because this polar group can increase the interaction between the molecular chains and restrict the movement of polymer chain segments.

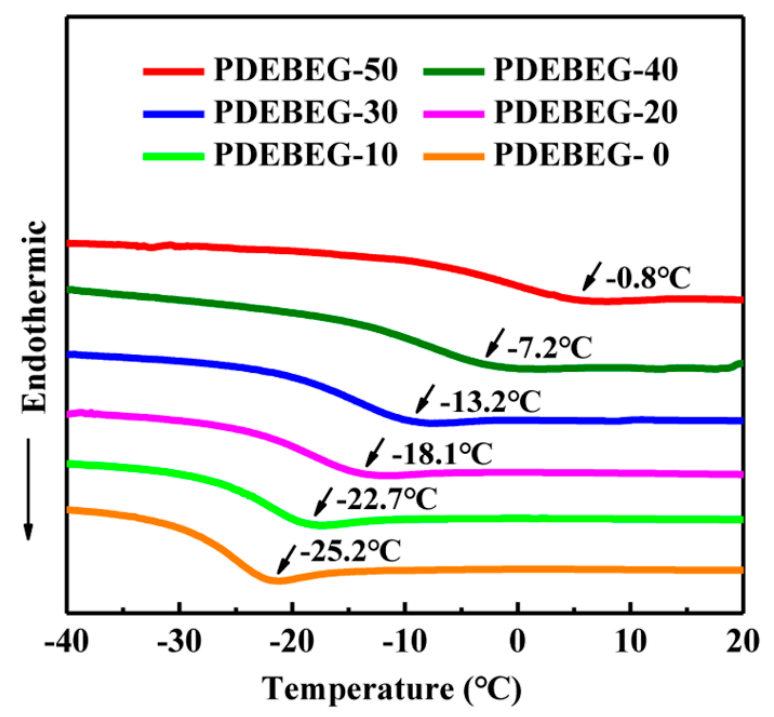

Figure 5. DSC thermograms of PDEBEG with different diethyl itaconate contents. 
The thermal stability of the PDEBEG was investigated by thermogravimetric analysis (TGA). The TGA and TGA derivative curves of PDEBEG measured from 30 to $800{ }^{\circ} \mathrm{C}$ are shown in Figure 6, and the thermal properties of the PDEBEG are listed in Table 4. The initial decomposition temperature is about $300{ }^{\circ} \mathrm{C}$. The $5 \%$ weight loss and the maximum decomposition temperatures range from 346-363 ${ }^{\circ} \mathrm{C}$ and $385-411^{\circ} \mathrm{C}$, respectively. With the introduction of the DEI, the thermal decomposition temperature of the PDEBEG gradually decreases, indicating that the ester groups in diethyl itaconate reduce the thermal stability of the PDEBEG.
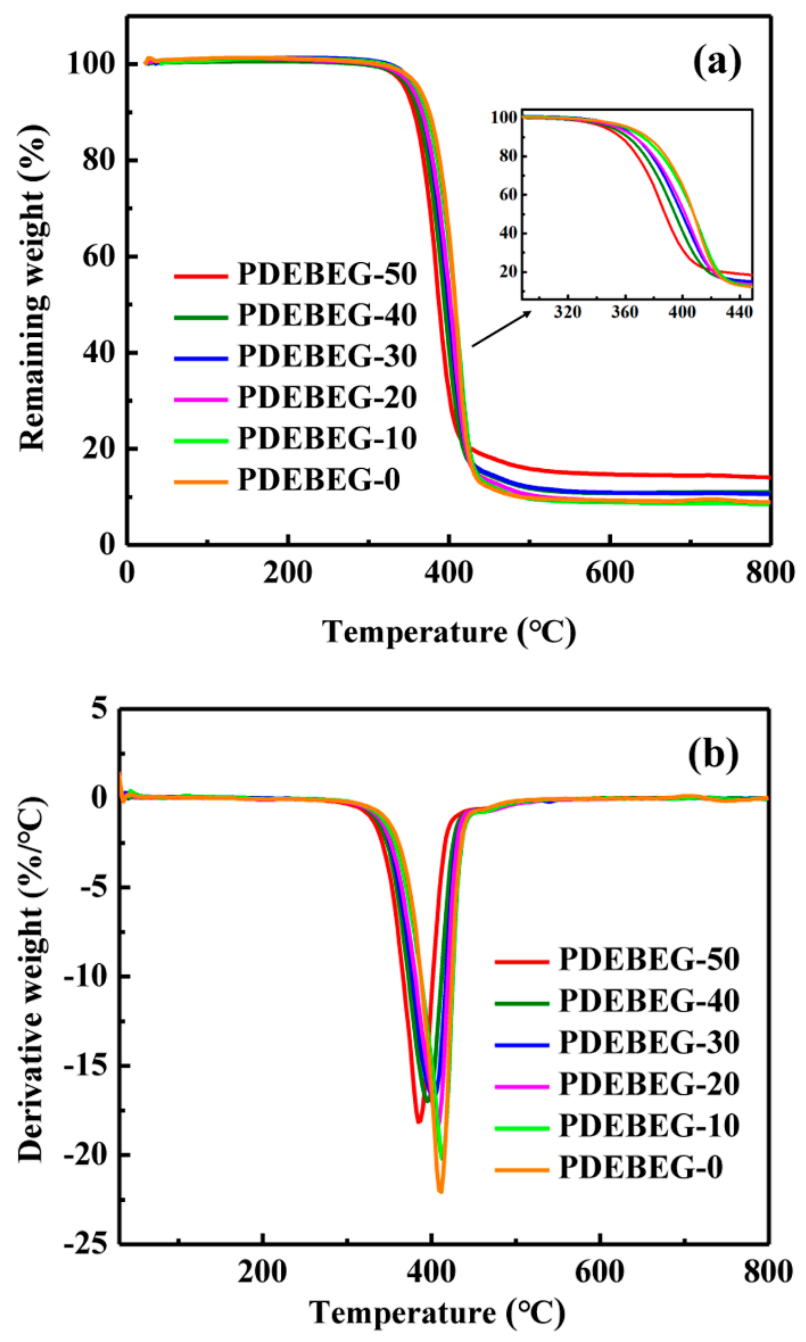

Figure 6. (a) TGA and (b) TGA derivative curves of PDEBEG.

Table 4. Thermal properties of PDEBEG.

\begin{tabular}{ccccccc}
\hline Samples & PDEBEG-50 & PDEBEG-40 & PDEBEG-30 & PDEBEG-20 & PDEBEG-10 & PDEBEG-0 \\
\hline $\mathrm{T}_{\mathrm{d}, 5 \%}{ }^{\mathrm{a}}$ & 346 & 350 & 357 & 354 & 360 & 363 \\
$\mathrm{~T}_{\mathrm{d}, \max }{ }^{\mathrm{a}}$ & 385 & 395 & 403 & 407 & 413 & 416 \\
\hline
\end{tabular}

${ }^{\text {a }}$ Temperature at which a $5 \%$ weight loss was observed in the TGA traces recorded at $10^{\circ} \mathrm{C} / \mathrm{min} .{ }^{\mathrm{b}}$ Temperature of maximum degradation rate.

\subsection{Vulcanization Characteristics, Morphology, and Mechanical Properties of the PDEBEG/CB Composites}

Most elastomer products are useless unless properly cured. Since the modulus of the elastomer increases dramatically during curing, it is used to monitor the curing progress. Table 5 shows the characteristic curing data for the PDEBEG with various DEI contents and AR72LS (prepared in the same way as the PDEBEG composites) at $180{ }^{\circ} \mathrm{C}$. As the fraction of the DEI decreases, the torque 
difference increases and the optimum cure time (the time when the torque reaches $90 \%$ of the maximum torque) increases, indicating an increase in crosslink density.

Table 5. Curing parameters for the PDEBEG/CB and AR72LS/CB elastomers.

\begin{tabular}{cccc}
\hline Sample & Scorch Time (min:s) & Curing Time (min:s) & Torque Increase (dNm) \\
\hline PDEBEG-50 & $0: 40$ & $13: 24$ & 10.3 \\
PDEBEG-40 & $0: 11$ & $9: 46$ & 14.0 \\
PDEBEG-30 & $1: 23$ & $17: 23$ & 12.7 \\
PDEBEG-20 & $1: 04$ & $15: 23$ & 12.5 \\
PDEBEG-10 & $0: 16$ & $14: 23$ & 20.0 \\
PDEBEG-0 & $1: 46$ & 21.50 & 18.5 \\
AR72LS & $3: 03$ & $19: 17$ & 19.0 \\
\hline
\end{tabular}

Figure 7 shows the strain amplitude dependence of $\mathrm{G}^{\prime}$ of the unvulcanized PDEBEG/CB compounds. In the filled elastomers, the structure of the filler-filler networks can be reflected by the Payne effect, which is referred to as the strain dependence of the $G^{\prime}$. The $G^{\prime}$ value decreases sharply when the filler-filler networks are broken after the strain reaches a critical value. The initial $\mathrm{G}^{\prime}$ of the PDEBEG/CB decreases with the increase of the DEI content due to the improvement of the CB dispersion. As the DEI content increases, the gel content of the PDEBEG decreases, resulting in weak filler-filler network and decreased initial G' of the PDEBEG/CB.

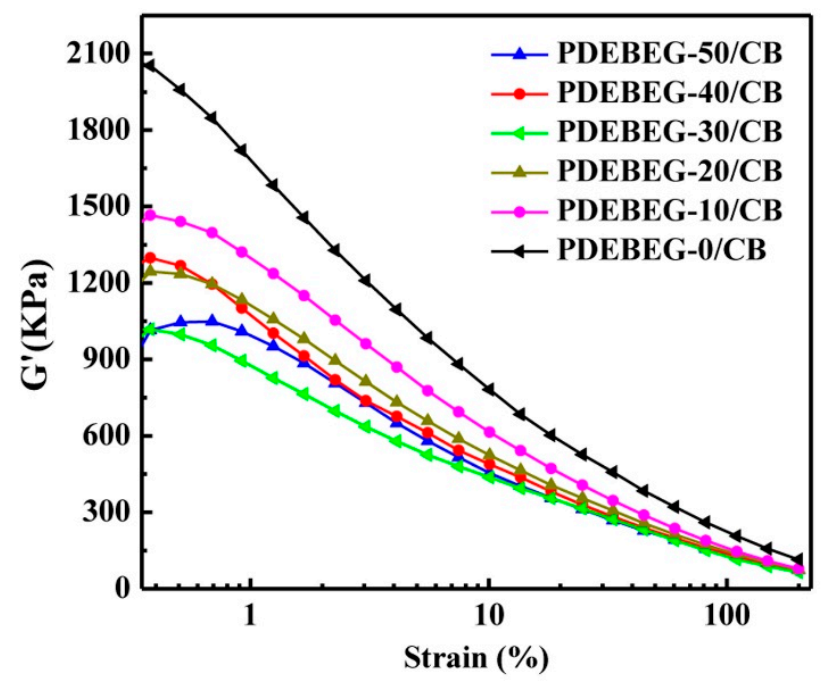

Figure 7. Strain amplitude dependence of $\mathrm{G}^{\prime}$ of the PDEBEG/CB compounds.

The dispersion of a filler in the matrix is an important factor for a composite to achieve high performance. The SEM micrographs shown in Figure 8 exhibit the dispersion of CB in the PDEBEG/CB. The light spots in the micrographs are the CB particles. As observed in Figure 8a-f, the filler dispersion in the PDEBEG matrix is obviously improved with the incorporation of the DEI, which is mutually confirmed by the RPA results.

The typical stress-strain curves of the PDEBEG/CB with various DEI content and AR72LS/CB are shown in Figure 9, and Table 6 summarizes the acquired data. The results show the tensile strength of PDEBEG/CB increases with the decrease of the DEI content. The small permanent set (Table 6) indicates that the PDEBEG elastomers have good recovery ability. For the PDEBEG-10/CB, the tensile strength can reach $14.5 \mathrm{MPa}$, the elongation at break is up to $305 \%$, and the permanent deformation is only $10 \%$, indicating that the overall mechanical properties of the PDEBEG-10/CB are superior to those of the commercially available acrylate rubber AR72LS. 

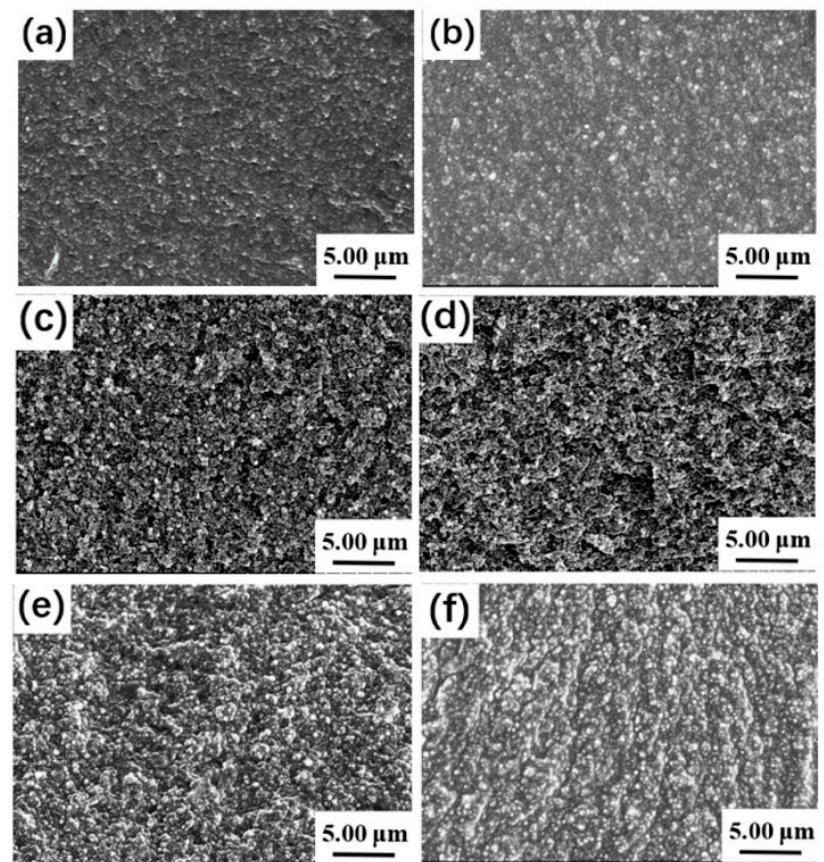

Figure 8. Scanning electron microscope graphs of (a) PDEBEG-50/CB, (b) PDEBEG-40/CB, (c) PDEBEG-30/CB, (d) PDEBEG-20/CB, (e) PDEBEG-10/CB, (f) PDEBEG-0/CB.

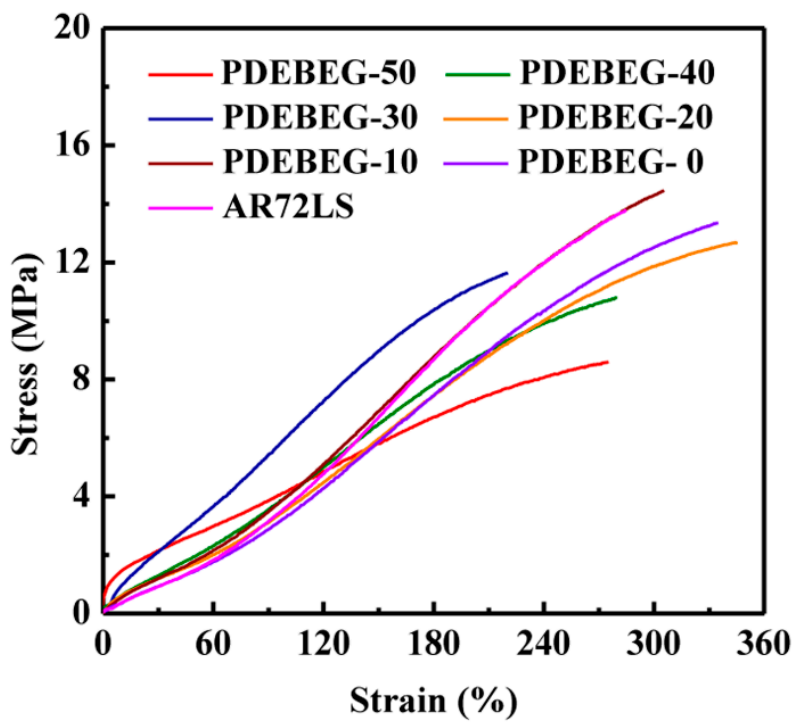

Figure 9. Stress-strain curves of the PDEBEG/CB and AR72LS/CB nanocomposites.

Table 6. Mechanical properties of the cross-linked PDEBEG/CB and AR72LS/CB elastomers.

\begin{tabular}{ccccc}
\hline Sample & $\begin{array}{c}\text { Tensile Strength } \\
\text { (MPa) }\end{array}$ & $\begin{array}{c}\text { Elongation at Break } \\
\mathbf{( \% )}\end{array}$ & Permanent Set (\%) & Hardness (Shore A) \\
\hline PDEBEG-50 & $8.4 \pm 0.2$ & $249 \pm 13$ & $8 \pm 2$ & $72 \pm 1$ \\
PDEBEG-40 & $10.8 \pm 0.2$ & $280 \pm 10$ & $8 \pm 1$ & $69 \pm 1$ \\
PDEBEG-30 & $11.4 \pm 0.3$ & $234 \pm 14$ & $6 \pm 2$ & $76 \pm 2$ \\
PDEBEG-20 & $12.7 \pm 0.3$ & $345 \pm 27$ & $12 \pm 2$ & $63 \pm 1$ \\
PDEBEG-10 & $14.5 \pm 0.4$ & $305 \pm 23$ & $10 \pm 1$ & $63 \pm 1$ \\
PDEBEG-0 & $13.8 \pm 0.3$ & $346 \pm 25$ & $12 \pm 1$ & $60 \pm 1$ \\
AR72LS & $13.8 \pm 0.2$ & $285 \pm 6$ & $12 \pm 2$ & $66 \pm 1$ \\
\hline
\end{tabular}




\subsection{Oil Resistance of the PDEBEG/CB Composites}

Since the PDEBEG is expected to replace the commercially available acrylate rubber and be used as an oil seal material at a high temperature, its oil resistance is also an important parameter to be evaluated. According to the test standard of oil-resistant rubber GB/T 1690-2010, the oil resistance test for the PDEBEG/CB was carried out using ASTM 3\# oil $\left(150^{\circ} \mathrm{C} \times 72 \mathrm{~h}\right)$. As shown in Figure 10, we can clearly compare the mechanical performance of the PDEBEG/CB with that of AR72LS/CB before and after soaking. Table 7 shows the retention of tensile strength, elongation at break, and hardness of the PDEBEG, which are reduced after soaking. Both the quality and volume of the PDEBEG increased after soaking because of the swelling of the elastomer network. The above Figure 10 and Table 7 show that the mechanical properties and oil resistance of the PDEBEG/CB with 10-20 wt $\%$ DEI are comparable to those of the commercially available acrylate AR72LS. The content of ester groups and the cross-linking density are the main factors affecting oil resistance. Molecular chains with polar ester groups can contribute to oil resistance, while molecular networks with high cross-linking density can inhibit the penetration of oil. The presence of DEI units affects both the ester group content and the cross-linking density of the PDEBEG. The presence of a diester group in the DEI structure makes the PDEBEG a high ester group content, which is advantageous to the oil resistance of the PDEBEG. However, the cross-linking density is lowered due to the steric hindrance effect of the diester groups, which is disadvantageous to the oil resistance of the PDEBEG.
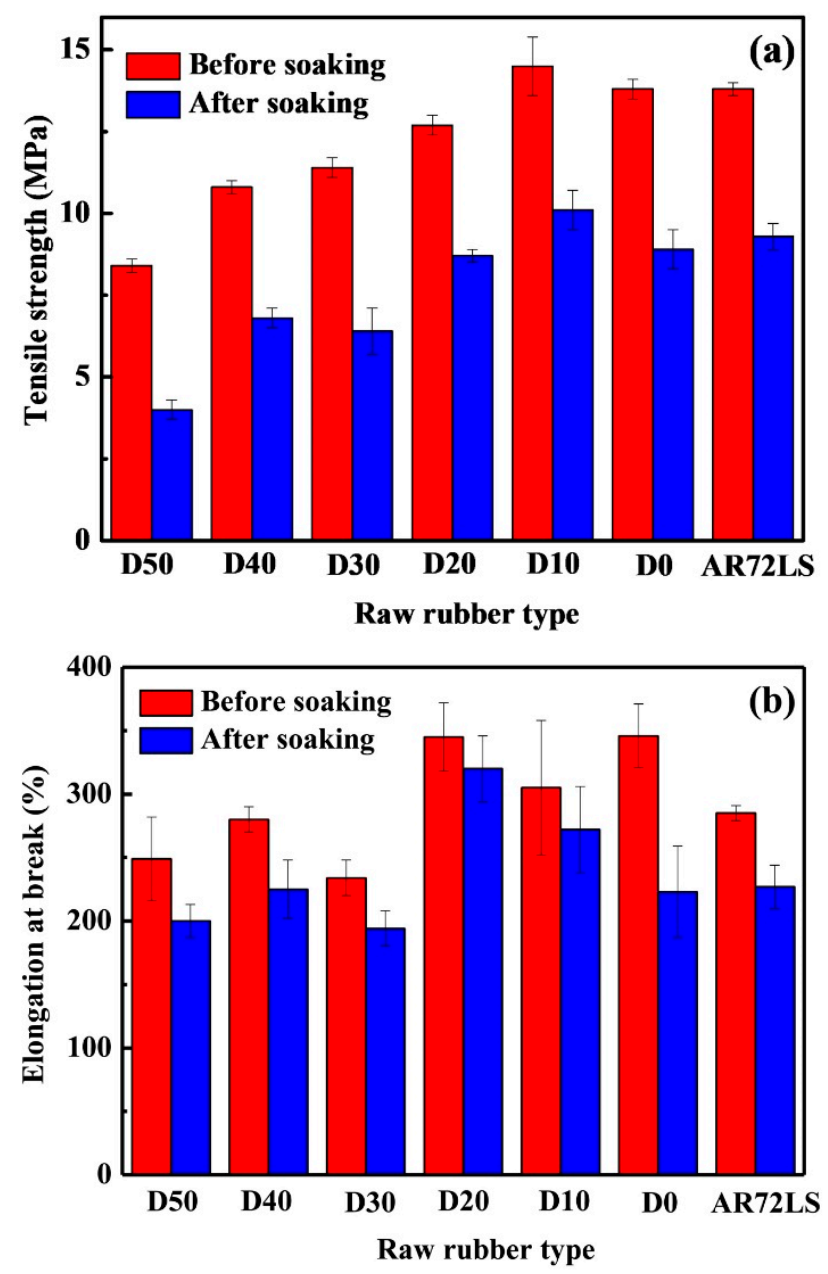

Figure 10. Mechanical performance comparison histogram before and after soaking, (a) tensile strength, (b) elongation at break. (The D50, D40, D30, D20, D10 and D0 refer to PDEBEG-50/CB, PDEBEG-40/CB, PDEBEG-30/CB, PDEBEG-20/CB, PDEBEG-10/CB, PDEBEG-0/CB, respectively.) 
Table 7. Retention of mechanical properties of PDEBEG/CB and AR72LS/CB vulcanizates before and after soaking in ASTM $3 \#$ oil at $150^{\circ} \mathrm{C}$ for $72 \mathrm{~h}$.

\begin{tabular}{cccccc}
\hline Sample & $\begin{array}{c}\text { Retention Rate of } \\
\text { Tensile Strength (\%) }\end{array}$ & $\begin{array}{c}\text { Retention Rate of } \\
\text { Elongation at Break (\%) }\end{array}$ & $\begin{array}{c}\text { Retention Rate of } \\
\text { Shore A Hardness (\%) }\end{array}$ & $\boldsymbol{\Delta m}(\%)$ & $\boldsymbol{\Delta V}(\%)$ \\
\hline PDEBEG-50 & 47.6 & 80.3 & 72.2 & +19.6 & +23.7 \\
\hline PDEBEG-40 & 63.0 & 80.4 & 75.4 & +18.5 & +17.6 \\
PDEBEG-30 & 56.1 & 82.9 & 69.7 & +19.2 & +18.8 \\
PDEBEG-20 & 68.5 & 92.8 & 88.9 & +16.9 & +12.5 \\
PDEBEG-10 & 69.7 & 89.2 & 92.1 & +13.8 & +9.9 \\
PDEBEG-0 & 64.5 & 64.5 & 86.7 & +18.5 & +16.7 \\
AR72LS & 67.4 & 79.6 & 86.4 & +18.0 & +14.0 \\
\hline
\end{tabular}

\section{Conclusions}

Novel oil-resistant elastomers (PDEBEG) with bio-based diethyl itaconate, butyl acrylate and ethyl acrylate as main monomers were designed and synthesized by redox emulsion polymerization. As the content of diethyl itaconate increased, the gel content obviously decreased and the dispersion of filler improved greatly, while the thermal stability of the PDEBEG gradually reduced. For the PDEBEG with $10 \mathrm{wt} \%$ diethyl itaconate, the number average molecular weight is 497,000 , the conversion rate is over $96 \%$, the glass transition temperature is $-22.7^{\circ} \mathrm{C}$, the tensile strength is up to $14.5 \mathrm{MPa}$, and the elongation at break can reach $305 \%$. The PDEBEG/CB composites were subjected to a high-temperature oil test at $150{ }^{\circ} \mathrm{C}$ for $72 \mathrm{~h}$. The results show that high-temperature oil resistance of PDEBEG-10 and PDEBEG-20 is superior to that of the commercially available acrylate rubber AR72LS. Overall, the novel PDEBEG is a promising candidate for the next generation of oil-resistant rubber.

Author Contributions: Conceptualization, W.L., L.Z., and R.W.; formal analysis, H.Y. and X.Z.; funding acquisition, W.L. and R.W.; investigation, H.Y. and H.J.; project administration, L.Z.; supervision, R.W.; validation, R.W.; writing—original draft, H.Y.; writing—review and editing, X.Z. and R.W.

Funding: This work was supported by the National Key Research and Development Program of China (2017YFB0306903), and the National Natural Science Foundation of China (51803051, 51503010).

Conflicts of Interest: The authors declare no conflicts of interest.

\section{References}

1. Patil, A.O.; Coolbaugh, T.S. Elastomers: A literature review with emphasis on oil resistance. Rubber Chem. Technol. 2005, 78, 516-535. [CrossRef]

2. Liu, X.; Zhao, J.; Yang, R.; Lervolino, R.; Barbera, S. Effect of lubricating oil on thermal aging of nitrile rubber. Polym. Degrad. Stab. 2018, 151, 136-143. [CrossRef]

3. Zhao, X.; Xiang, P.; Tian, M.; Fong, H.; Jin, R.; Zhang, L. Nitrile butadiene rubber/hindered phenol nanocomposites with improved strength and high damping performance. Polymer 2007, 48, 6056-6063. [CrossRef]

4. Rajasedkar, R.; Pal, K.; Heinrich, G.; Das, A.; Das, C.K. Development of nitrile butadiene rubber-nanoclay composites with epoxidized natural rubber as compatibilizer. Mater. Des. 2009, 30, 3839-3845.

5. Zhang, X.; Li, H.; Tian, D.; He, X.; Lu, C.H. Enhancement of thermal aging performance and oil resistance of acrylic rubber vulcanisates by adding devulcanised ground fluoroelastomer ultrafine powder as functional filler. Mater. Res. Innov. 2012, 16, 143-149. [CrossRef]

6. Wen, X.; Yuan, X.; Lan, L.; Hao, L.; Li, S.; Zheng, Z. Effect of transformer oil on room temperature vulcanized silicone rubber. IEEE Trans. Dielectr. Electr. Insul. 2017, 24, 2337-2343. [CrossRef]

7. Wang, Y.; Bi, L.; Zhang, H.; Zhu, X.; Liu, G.; Qiu, G.; Liu, S. Predictive power in oil resistance of fluororubber and fluorosilicone rubbers based on three-dimensional solubility parameter theory. Polym. Test. 2019, 75, 380-386. [CrossRef]

8. Ismail, S.; Chatterjee, T.; Naskar, K. Superior heat-resistant and oil-resistant blends based on dynamically vulcanized hydrogenated acrylonitrile butadiene rubber and polyamide 12. Polym. Adv. Technol. 2017, 28, 665-678. [CrossRef] 
9. Yeo, Y.G.; Park, H.H.; Lee, C.S. A study on the characteristics of a rubber blend of fluorocarbon rubber and hydrogenated nitrile rubber. J. Ind. Eng. Chem. 2013, 19, 1540-1548. [CrossRef]

10. Wang, J.; Li, H.; Zhang, L.; Lai, X.; Wu, W.; Zeng, X. In situ preparation of reduced graphene oxide reinforced acrylic rubber by self-assembly. J. Appl. Polym. Sci. 2019, 136, 47187. [CrossRef]

11. Jha, A.; Dutta, B.; Bhowmick, A. Effect of fillers and plasticizers on the performance of novel heat and oil-resistant thermoplastic elastomers from nylon-6 and acrylate rubber blends. J. Appl. Polym. Sci. 1999, 74, 1490-1501. [CrossRef]

12. Jha, A.; Bhowmick, A.K. Mechanical and dynamic mechanical thermal properties of heat- and oil-resistant thermoplastic elastomeric blends of poly (butylene terephthalate) and acrylate rubber. J. Appl. Polym. Sci. 2000, 78, 1001-1008. [CrossRef]

13. Hu, S.; Chen, S.; Zhao, X.; Guo, M.; Zhang, L. The shape-memory effect of hindered phenol (AO-80)/acrylic rubber (ACM) composites with tunable transition temperature. Materials 2018, 11, 2461. [CrossRef] [PubMed]

14. Qiu, Z.; Qin, C.; Qiu, J. Study on application of the blends of nitrile rubber with acrylate rubber in the coat-metal sealing gasket. Adv. Mater. Res. 2012, 393, 1438-1442. [CrossRef]

15. Wilfredo, Y.; Anna, S.; Nancy, Y.; Zbigniew, R. Design, synthesis, characterization and optimization of PTT-b-PEO copolymers: A new membrane material for $\mathrm{CO}_{2}$ separation. J. Membr. Sci. 2010, 362, 407-416.

16. Buchard, A.; Bakewell, C.M.; Weiner, J.; Williams, C.K. Recent developments in catalytic activation of renewable resources for polymer synthesis. Organomet. Renew. 2012, 39, 175-224.

17. Willke, T. Biotechnological production of itaconic acid. Appl. Microbiol. Biotechnol. 2001, 56, $289-295$. [CrossRef]

18. Lee, J.; Kim, H.; Choi, S.; Yi, J.; Lee, S. Microbial production of building block chemicals and polymers. Curr. Opin. Biotechnol. 2011, 22, 758-767. [CrossRef]

19. Choi, S.; Song, C.; Shin, J.; Lee, S. Biorefineries for the production of top building block chemicals and their derivatives. Metab. Eng. 2015, 28, 223-239. [CrossRef]

20. Wang, J.; Qian, W.; He, Y.; Xiong, Y.; Song, P.; Wang, R.M. Reutilization of discarded biomass for preparing functional polymer materials. Waste Manag. 2017, 65, 11-21. [CrossRef]

21. Dong, W.; Li, T.; Xiang, S.; Ma, P.; Chen, M. Influence of glutamic acid on the properties of poly (xylitol glutamate sebacate) bioelastomer. Polymers 2013, 5, 1339-1351. [CrossRef]

22. Dai, L.; Tai, C.; Shen, Y.; Guo, Y.; Tao, F. Biosynthesis of 1,4-butanediol from erythritol using whole-cell catalysis. Biocatal. Biotransform. 2019, 37, 92-96. [CrossRef]

23. Wang, G.; Jiang, M.; Zhang, Q.; Wang, R.; Liang, Q.; Zhou, G. New bio-based copolyesters derived from 1,4-butanediol, terephthalic acid and 2, 5-thiophenedicarboxylic acid: Synthesis, crystallization behavior, thermal and mechanical properties. Polym. Test. 2019, 75, 213-219. [CrossRef]

24. Wang, R.; Ma, J.; Zhou, X.; Wang, Z.; Kang, H.; Zhang, L.; Hua, K.C.; Kulig, J. Design and preparation of a novel cross-linkable, high molecular weight, and bio-based elastomer by emulsion polymerization. Macromolecules 2012, 45, 6830-6839. [CrossRef]

25. Wang, R.; Yao, H.; Lei, W.; Zhou, X.; Zhang, L.; Hua, K.C.; Kulig, J. Morphology, interfacial interaction, and properties of a novel bioelastomer reinforced by silica and carbon black. J. Appl. Polym. Sci. 2013, 129, 1546-1554. [CrossRef]

26. Wang, Z.; Zhang, X.; Zhang, L.; Tan, T.; Fong, H. Nonisocyanate biobased poly(ester urethanes) with tunable properties synthesized via an environment-friendly route. ACS Sustain. Chem. Eng. 2016, 4, 2762-2770. [CrossRef]

27. Okabe, M.; Lies, D.; Kanamasa, S.; Park, E.Y. Biotechnological production of itaconic acid and its biosynthesis in aspergillus terreus. Appl. Microbiol. Biotechnol. 2009, 84, 597-606. [CrossRef]

28. Kuenz, A.; Gallenmuller, Y.; Willke, T.; Vorlop, K.D. Microbial production of itaconic acid: Developing a stable platform for high product concentrations. Appl. Microbiol. Biotechnol. 2012, 96, 1209-1216. [CrossRef]

29. Wei, T.; Lei, L.; Kang, H.; Qiao, B.; Wang, Z.; Zhang, L.; Coates, P.; Hua, K.C.; Kulig, J. Tough bio-based elastomer nanocomposites with high performance for engineering applications. Adv. Eng. Mater. 2012, 14, 112-118. [CrossRef]

30. Guo, B.; Chen, Y.; Lei, Y.; Zhang, L.; Zhou, W.; Rabie, A.B.; Zhao, J. Biobased poly (propylene sebacate) as shape memory polymer with tunable switching temperature for potential biomedical applications. Biomacromolecules 2011, 12, 1312-1321. [CrossRef] 
31. Tsujimoto, T.; Uyama, H. Full biobased polymeric material from plant oil and poly (lactic acid) with a shape memory property. ACS Sustain. Chem. Eng. 2014, 2, 2057-2062. [CrossRef]

32. Farmer, T.J.; Castle, R.L.; Clark, J.H.; Macquarrie, D.J. Synthesis of unsaturated polyester resins from various bio-derived platform molecules. Int. J. Mol. Sci. 2015, 16, 14912-14932. [CrossRef] [PubMed]

33. Gao, L.; Zheng, G.; Nie, X.; Wang, Y. Thermal performance, mechanical property and fire behavior of epoxy thermoset based on reactive phosphorus-containing epoxy monomer. J. Therm. Anal. Calorim. 2017, 127, 1419-1430. [CrossRef]

34. Wang, Z.; Wei, T.; Xue, X.; He, M.; Xue, J.; Song, M.; Wu, S.; Kang, H.; Zhang, L.; Jia, Q. Synthesis of fully bio-based polyamides with tunable properties by employing itaconic acid. Polymer 2014, 55, 4846-4856. [CrossRef]

35. Maisonneuve, L.; Lebarbe, T.; Grau, E.; Cramail, H. Structure-properties relationship of fatty acid-based thermoplastics as synthetic polymer mimics. Polym. Chem. 2013, 4, 5472-5517. [CrossRef]

36. Lei, W.; Russell, T.P.; Hu, L.; Zhou, X.; Qiao, H.; Wang, W.; Wang, R.; Zhang, L. Pendant chain effect on the synthesis, characterization, and structure-property relations of poly (di-n-alkyl itaconate-coisoprene) biobased elastomers. ACS Sustain. Chem. Eng. 2017, 5, 5214-5223. [CrossRef]

37. Qiao, H.; Xu, W.; Chao, M.; Liu, J.; Lei, W.; Zhou, X.; Wang, R.; Zhang, L. Preparation and performance of silica/epoxy group-functionalized biobased elastomer nanocomposite. Ind. Eng. Chem. Res. 2017, 56, 881-889. [CrossRef]

38. Durant, Y.; Jiang, B.; Tsavalas, J. Emilsion Polymerization of Ester of Itaconic Acid. U.S. Patent US9932421B2, 3 Apirl 2018.

39. Chakraborty, S.; Ramakrishnan, S. Surface-Functionalized Polystyrene Latexes Using Itaconate-Based Surfmers. Langmuir 2018, 34, 11729-11737. [CrossRef]

40. Qiao, Z.; Qiu, T.; Liu, W.; Zhang, L.; Tu, J.; Guo, L.; Li, X. A “green” method for preparing ABCBA pentablock elastomers by using RAFT emulsion polymerization. Polym. Chem. 2017, 8, 3013-3021. [CrossRef]

41. Schmidt, B.; Molinari, V.; Esposito, D.; Tauer, K.; Antonietti, M. Lignin-based polymeric surfactants for emulsion polymerization. Polymer 2017, 112, 418-426. [CrossRef]

42. Fernandez, A.M.; Held, U.; Willing, A.; Breuer, W.H. New green surfactants for emulsion polymerization. Prog. Org. Coat. 2005, 53, 246-255. [CrossRef]

43. Lei, W.; Qiao, H.; Zhou, X.; Wang, W.; Zhang, L.; Wang, R.; Hua, K.C. Synthesis and evaluation of bio-based elastomer based on diethyl itaconate for oil-resistance applications. Sci. China Chem. 2016, 59, 1376-1383. [CrossRef]

(C) 2019 by the authors. Licensee MDPI, Basel, Switzerland. This article is an open access article distributed under the terms and conditions of the Creative Commons Attribution (CC BY) license (http://creativecommons.org/licenses/by/4.0/). 